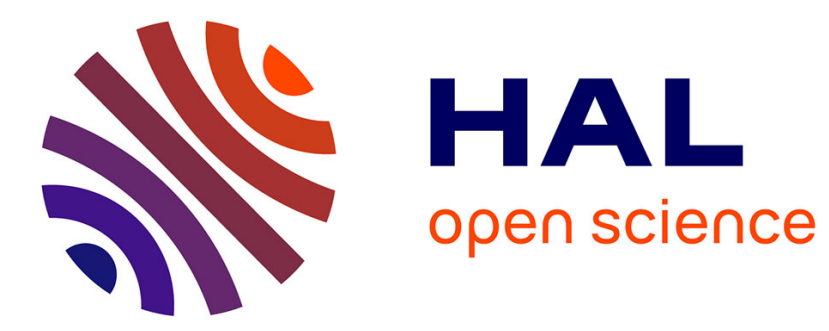

\title{
Wet Chemistry of Spinel Iron oxide Particles
}

\author{
J. Jolivet, Corinne Chanéac, P. Prené, L. Vayssières, E. Tronc
}

\section{To cite this version:}

J. Jolivet, Corinne Chanéac, P. Prené, L. Vayssières, E. Tronc. Wet Chemistry of Spinel Iron oxide Particles. Journal de Physique IV Proceedings, 1997, 07 (C1), pp.C1-573-C1-576. 10.1051/jp4:19971236 . jpa-00254920

\section{HAL Id: jpa-00254920 https://hal.science/jpa-00254920}

Submitted on 1 Jan 1997

HAL is a multi-disciplinary open access archive for the deposit and dissemination of scientific research documents, whether they are published or not. The documents may come from teaching and research institutions in France or abroad, or from public or private research centers.
L'archive ouverte pluridisciplinaire HAL, est destinée au dépôt et à la diffusion de documents scientifiques de niveau recherche, publiés ou non, émanant des établissements d'enseignement et de recherche français ou étrangers, des laboratoires publics ou privés. 


\title{
Wet Chemistry of Spinel Iron oxide Particles
}

\author{
J.P. Jolivet, C. Chanéac, P. Prené, L. Vayssières and E. Tronc \\ Chimie de la Matière Condensée, URA 1466 du CNRS, Université Pierre et Marie Curie, T54 - E5, \\ 4 place Jussieu, 75252 Paris cedex 05, France
}

\begin{abstract}
Various properties of spinel iron oxide nanograins are reviewed, illustrating the broad possibilities of wet chemistry for tailoring materials for a wide range of utilizations, from catalysis and sensors to cast magnetic materials.
\end{abstract}

\section{INTRODUCTION}

The properties of finely divided materials closely depend on the size of the particles and their state of dispersion and aggregation. It is therefore essential to master the synthesis of the particles and to control their surface state. The synthesis from solution offers some advantages : mild conditions, easy control of the particle size and composition, various possibilities of modifying the surface state allowing to obtain stable dispersions in various liquid or solid media. However, care must be taken in order to obtain well-defined materials with controlled properties.

The spinel iron oxides, $\mathrm{Fe}_{3} \mathrm{O}_{4}-\gamma$ - $\mathrm{Fe}_{2} \mathrm{O}_{3}$, are in some sense a model system because most of the basic phenomena involved in the physico-chemistry of fine oxide particles are especially enhanced [1-8].

\section{SYNTHESIS BY COPRECIPITATION}

Various $\mathrm{Fe}^{3+}$-based spinel ferrites can be obtained by coprecipitating $\mathrm{Fe}^{3+}$ ions with divalent cations, $\mathrm{M}^{2+}$, in alkaline medium. In general, $\mathrm{M}^{2+}(\mathrm{M}=\mathrm{Mn}, \mathrm{Co}, \mathrm{Ni}, \mathrm{Cu}, \mathrm{Zn})$ ions have a behaviour in solution that is largely different from that of $\mathrm{Fe}^{3+}$ ions regarding, in particular, their acid-base properties and tendency to condense [9], and ferrite formation is not straightforward. The initial precipitate is a very poorly crystallized $\mathrm{M}$-ferrihydrite or a mixture of $\mathrm{M}(\mathrm{OH})_{2}$ and ferrihydrite, which yields the ferrite by dissolution-reprecipitation [10]. It is necessary to operate at 50 to $100^{\circ} \mathrm{C}$ with the $\mathrm{M}^{2+} / \mathrm{Fe}^{3+}$ ratio equal to 0.5 or at least larger than $0.3(\mathrm{Co}, \mathrm{Cu})$ in order to obtain only the ferrite.

With $\mathrm{Fe}^{2+}$ ions at stoichiometry $\mathrm{x}=\mathrm{Fe}^{2+} / \mathrm{Fe}^{3+}=0.5$, crystallization of stoichiometric $\mathrm{Fe}_{3} \mathrm{O}_{4}$ is quasi-immediate at room temperature. $\gamma-\mathrm{Fe}_{2} \mathrm{O}_{3}$ does not form directly in solution but a small proportion of $\mathrm{Fe}^{2+}$ ions $(\mathrm{x}=0.10)$ is sufficient to crystallize all the iron into spinel $[1,2]$. Studies of the early precipitate revealed a two-phase system, spinel oxide $(x \geq 0.40)$ and mixedvalence $\mathrm{Fe}^{2+}$-ferrihydrite $(\mathrm{x} \leq 0.20)$. The latter material is a very poorly crystallized oxyhydroxide is structurally and morphologically ( 2 to $3 \mathrm{~nm}$ particles) similar to ferric ferrihydrite. However, at $\mathrm{x} \leq 0.20$, all Fe $\mathrm{F}^{2+}$ ions are incorporated into the $\mathrm{Fe}^{2+}$-ferrihydrite and give rise to high electron mobility as evidenced by Mössbauer spectroscopy. This mixed valence material transforms with time into spinel by two simultaneous competing pathways :

- $i$ solid state reaction with dehydration and spinel ordering at short range, without particle size variation.

- $i$ i dissolution of $\mathrm{Fe}^{2+}-\mathrm{Fe}^{3+}$ complexes from the surface followed by crystallization of spinel oxide (Ostwald ripening). This process takes place with particle growth.

The phase resulting from process $i$ (Fig. 1a) has a low $\mathrm{Fe}^{2+}$ content $\left(\mathrm{Fe}^{2+} / \mathrm{Fe}^{3+} \sim 0.07\right)$. It is hydrated and very finely divided. The phase formed by process ii (Fig. lb) is rich in $\mathrm{Fe}^{2+}\left(\mathrm{Fe}^{2+} / \mathrm{Fe}^{3+} \sim 0.33\right)$ and well crystallized. Its amount and particle size (20 to $100 \mathrm{~nm}$ ) strongly depend upon the initial $x$ stoichiometry. The end products of the coprecipitation are single-phase only for $x \geq$ 0.33 . For such compositions, process $i i$ seems dominant during the evolution from the initial stage of precipitation as noticeable growth of particles is observed.

The comparison with the cases where $\mathrm{M}^{2+}$ is different from $\mathrm{Fe}^{2+}[10]$ emphasizes the role of the electron mobility between $\mathrm{Fe}^{2+}$ and $\mathrm{Fe}^{3+}$ ions in the crystallization process. Mobility in the bulk presumably drives a local cubic close-packed ordering [2] made possible by the loose structure of the early material. This local ordering gradually extends to the whole fine 
particle (process $i$ ), and to the growing particle (process $i$ ). With the other divalent cations, intervalence transfers are generally negligible and a spinel ferrite forms only by process $i i$. In addition, because of the different reactivities of $\mathrm{Fe}^{3+}$ and $\mathrm{M}^{2+}$ ions, the Ostwald ripening can bring about composition gradients within the particles as revealed by the progressive dissolution of particles giving a variable $\mathrm{M}^{2+} / \mathrm{Fe}^{3+}$ ratio [11].
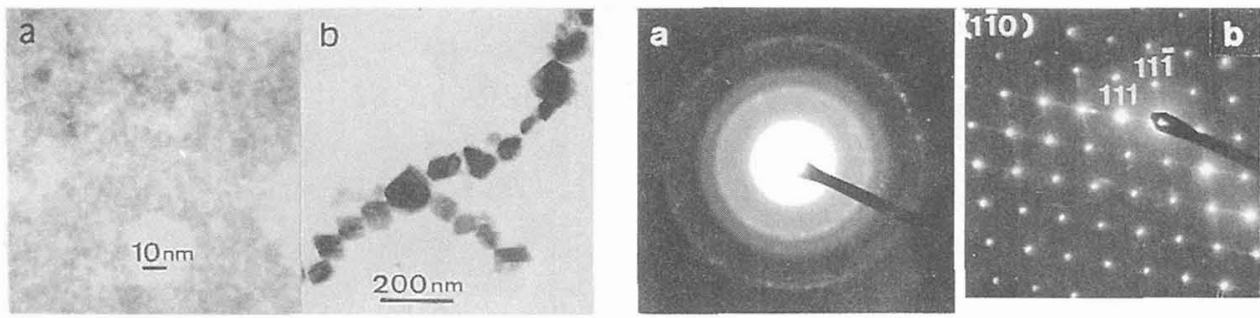

Figure 1 : Transmission electron microscopy images and diffraction patterns of the end products of the coprecipitation of $\mathrm{Fe}^{2+}$ and $\mathrm{Fe}^{3+}$ ions at $\mathrm{Fe}^{2+} / \mathrm{Fe}^{3+}=0.15$, formed by $\mathrm{a}$ : process $i$; $\mathrm{b}$ : process $i i$ (see text) and separated by centrifuging.

\section{SURFACE ACID-BASE PROPERTIES}

Most of the physico-chemical properties [9] of an oxide particle in aqueous medium are controlled by the proton adsorptiondesorption equilibria at the solid-solution interface. The surface acid-base reactions, of the type

$$
-\mathrm{Fe}-\mathrm{OH}_{2}^{+}+\mathrm{HO}^{-} \Leftrightarrow-\mathrm{Fe}-\mathrm{OH}+\mathrm{H}_{2} \mathrm{O} \Leftrightarrow-\mathrm{Fe}-\mathrm{O}^{-}+\mathrm{H}_{3} \mathrm{O}^{+}
$$

generate a surface electric charge. The actual phenomena are complex and a given surface site is unlikely to be amphoteric. In a first approximation, it suffices to consider the net surface charge. It depends in magnitude and sign on the $\mathrm{pH}$ of the medium, being zero at $\mathrm{pH}=\mathrm{PZC}$ (Point of Zero Charge), positive at $\mathrm{pH}<\mathrm{PZC}$ and negative at $\mathrm{pH}>\mathrm{PZC}$. At fixed ionic strength, $\mathrm{I}$, imposed by the medium, the magnitude of the charge, $\sigma$, increases with increasing $\Delta \mathrm{pH}=\mathrm{lpH}-\mathrm{PZCl}$, up to a maximum value, $\sigma_{\max }$, which depends on the structure and composition of the surface. At fixed $\mathrm{pH}, \sigma$ varies with I through a screening effect between charged sites which depends on the size, charge and concentration of the counterions balancing the surface charge of the particle. The surface charge promotes strong interactions with water molecules. Through the screening effect, the counterions influence the structure and extension of the solvation layer.

For the spinel iron oxides, PZC is of the order of 7, and $\sigma_{\max }$ is typically of the order of $1 \mathrm{C} \mathrm{m}^{-2}$ [12]. $\mathrm{Fe}_{3} \mathrm{O}_{4}$ particles cannot acquire a notable positive charge in acidic medium without transforming into $\gamma$ - $\mathrm{Fe}_{2} \mathrm{O}_{3}$ (part 5), but $\gamma$ - $\mathrm{Fe}_{2} \mathrm{O}_{3}$ particles are stable far from the PZC in both alkaline and acidic media.

\section{SIZE CONTROL}

In general, the synthesis of monodispersed particles is performed under a kinetic control of the precipitation by using, for instance, very dilute solutions, the transitory precipitation of another phase, or thermohydrolysis conditions [13]. However, the a priori control of the particle size at the nanometric scale is hardly achievable. A thermodynamic control of the size [14], through the interfacial tension lowering, is rarely considered. Our studies on stoichiometric magnetite $[3,4]$ showed that it can be operative.

The oxide-solution interfacial tension depends on the chemical composition of the surface, which directly depends on the proton adsorption-desorption equilibria and, consequently, on the surface charge and, hence, on $\mathrm{pH}$ and $\mathrm{I}$. An increase in $\mathrm{pH}$ or I decreases the interfacial tension, stabilizing an interface of large extension.

The size of $\mathrm{Fe}_{3} \mathrm{O}_{4}$ particles is strongly dependent on the $\mathrm{pH}$ and the ionic strength of the precipitation medium. At fixed $\mathrm{I}$, the particle size decreases with increasing $\mathrm{pH}$ (Fig.2a). At fixed $\mathrm{pH}$, the size decreases with increasing $\mathrm{I}$ (Fig.2b). Above a critical $\mathrm{pH}$, dependent on the ionic strength, no secondary growth takes place under aging in the $\mathrm{pH}$ and $\mathrm{I}$ conditions of synthesis. Particles aged in $\mathrm{pH}$ and $\mathrm{I}$ conditions different from the $\mathrm{pH}$ and I conditions of synthesis increase or decrease in size according to the variation of the conditions, and reach the same size as if the aging conditions have been the synthesis conditions. All phenomena have been interpreted quantitavely by applying basic laws of thermodynamics and a model derived from that of Stol and De Bruyn [14].

Our results $[3,4]$ show that the size of $\mathrm{Fe}_{3} \mathrm{O}_{4}$ particles can be controlled, and stabilized against ripening, over nearly one order of magnitude at the nanometric scale $(1.5$ to $12 \mathrm{~nm}$ ) by adjusting the precipitation conditions. 

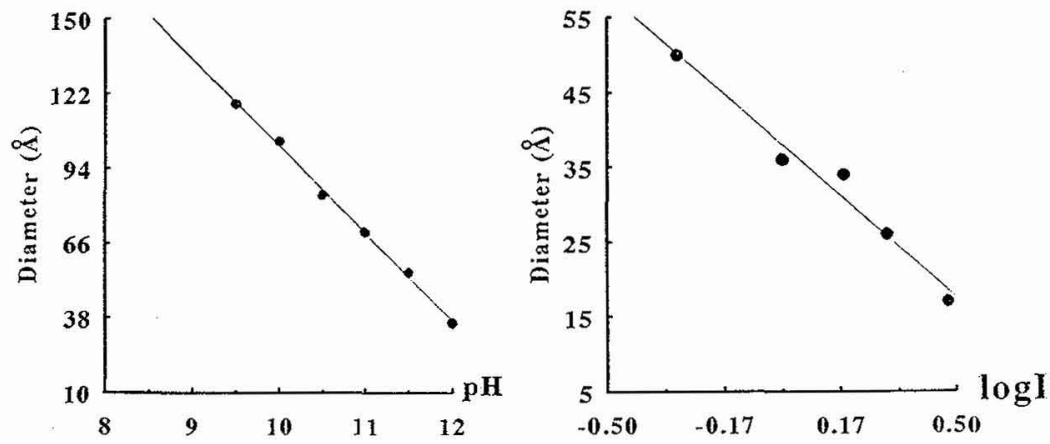

Figure 2 : Mean size of $\mathrm{Fe}_{3} \mathrm{O}_{4}$ particles formed at different $\mathrm{pH}(\mathrm{I}=0.5 \mathrm{M})$ (left) and different ionic strengths ( $\left.\mathrm{pH}=12\right)$ (right) after aging for 8 days at $25^{\circ} \mathrm{C}$.

\section{REDOX REACTIONS}

In general, the effects of an adsorption reaction remain limited to the surface of the particle. With mixed-valent systems, surface reactions can cause the response of the core.

Extensive redox reactions can take place at the surface of a particle of spinel iron oxide. The fast intervalence transfers between the $\mathrm{Fe}$ ions in the octahedral sublattice relay the electron transfer at the interface and feed the surface reaction. A great variety of adsorption reactions in solution can thus cause the complete conversion $\mathrm{Fe}_{3} \mathrm{O}_{4} \rightarrow \gamma-\mathrm{Fe}_{2} \mathrm{O}_{3}$. As in the case of dry oxidation [15], they start up a solid state reaction which makes the particle composition span the whole existence range of the spinel phase. The conversion can proceed

- without iron desorption, like in the case of adsorption of oxygen or oxygenated species, or of easily reducible and hydrolyzable species like $\mathrm{Ag}^{+}[16]$ with $\mathrm{Ag}$ metal particle formation

- with $\mathrm{Fe}^{2+}$ desorption, like in the case of proton adsorption in mild acidic conditions [5].

Because of the small size of the particles the conversion $\mathrm{Fe}_{3} \mathrm{O}_{4} \rightarrow \gamma-\mathrm{Fe}_{2} \mathrm{O}_{3}$, with rate determined by iron diffusion, goes up to completion more or less quickly depending on the particle size. Due to the large surface to volume ratio, the complete conversion, which involves $11 \%$ of the total iron reacting at the surface, proceeds with no notable variation of the size.

The interfacial electron transfer relayed by mixed valences is reversible. All the $\mathrm{Fe}^{2+}$ ions released from the $\mathrm{Fe}_{3} \mathrm{O}_{4}$ particle in acidic medium can be re-adsorbed onto the $\gamma-\mathrm{Fe}_{2} \mathrm{O}_{3}$ particle by rising the $\mathrm{pH}$ [5]. Adsorbed hydroxylated $\mathrm{Fe}^{2+}$ ions grow an epitaxial $\mathrm{Fe}_{3} \mathrm{O}_{4}$ layer. Electrons are injected into the bulk via $\mathrm{Fe}^{2+}-\mathrm{Fe}^{3+}$ electron transfers, and electroneutrality is kept by inward migration of cations, iron cations and more likely protons which diffuse more easily. Adsorption of $\mathrm{Co}^{2+}$ onto the $\gamma-$ $\mathrm{Fe}_{2} \mathrm{O}_{3}$ particle, which does not give rise to electron transfers, just yields a monoatomic layer of cobalt ferrite coating the $\gamma$ $\mathrm{Fe}_{2} \mathrm{O}_{3}$ particle. The redox behaviour of the $\mathrm{Fe}_{3} \mathrm{O}_{4}-\gamma-\mathrm{Fe}_{2} \mathrm{O}_{3}$ particles suggests catalytic potentialities.

\section{DISPERSIONS}

In aqueous medium, dispersal ability is ensured by the surface electric charge (part 3) which promotes electrostatic repulsions between the particles via the particle-solvent interactions. The repulsive forces between the particles are competing with the attractive forces (Van der Waals, magnetostatic) in determining the stability of the dispersion. The balance of the forces can easily be modulated by acting on the electrostatic repulsions through variations of the surface charge.

At $\mathrm{pH} \sim 2$ and low ionic strength $\left(10^{-2}-5 \times 10^{-2} \mathrm{M}\right)$, the surface charge density of $\gamma-\mathrm{Fe}_{2} \mathrm{O}_{3}$ particles is high enough for stable dispersions (sols) to form practically free from aggregation $[7,8]$. On raising the $\mathrm{pH}, \sigma$ decreases, the repulsions weaken, the degree of agglomeration increases (Fig.3). Aggregation remains limited provided $\mathrm{pH}<\mathrm{PZC}$. The aggregate configuration, depending on the $\mathrm{pH}$, ranges from small chain-like clusters of a few particles to branchy chains of more than ca. 50 particles. In every case, the structure is loose and the particles are not in close contact. At $\mathrm{pH}$ near PZC, $\sigma \sim 0$, a floc forms. At pH $>\mathrm{PZC}$, the particles re-disperse but aggregation is generally more significant than at $\mathrm{pH}<\mathrm{PZC}$. Dispersions in non-aqueous medium can be obtained by adapting the characteristics of the particle surface to those of the medium.

The dispersions can be gelled by adding a polymer soluble in the dispersion medium. Thus, in order to study the magnetic properties of non-interacting particles and interaction effects we prepared several series of composites made up $\gamma$ $\mathrm{Fe}_{2} \mathrm{O}_{3}$ particles dispersed in polyvinylic alcohol $[8,17]$. Each series was characterized by the same distribution of particle size and different states of aggregation/dispersion, typically non-aggregated particles in dilute and concentrated state, with a centre to centre distance of the order of 5 and 1.5 times the mean diameter, clusters of varying length and flocs. The average particle diameter varied from 3 to $10 \mathrm{~nm}$ between the series. The results $[8,17,18]$ allowed us to give the first demonstrative 
experimental verification of the Néel-Brown model for superparamagnetic relaxation [19,20]. We showed that the surface anisotropy $\left(\mathrm{K}_{\mathrm{S}}=0.06 \mathrm{erg} / \mathrm{cm}^{2}\right)$ is largely dominant. We characterized the effects of the interactions between particles and established the validity of Dormann's statistical model [21]. The results also pointed out notable effects of the surface spins.
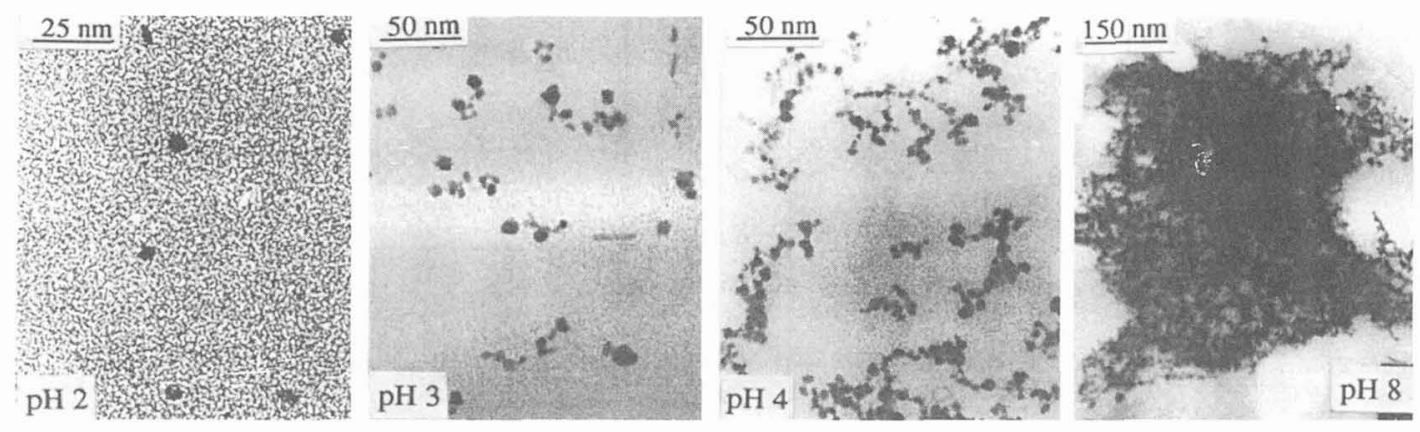

Figure 3 : TEM images of dispersions of $\gamma-\mathrm{Fe}_{2} \mathrm{O}_{3}$ particles in polyvinylic alcohol. Influence of the $\mathrm{pH}$ of the dispersion medium.

Composites with $\gamma-\mathrm{Fe}_{2} \mathrm{O}_{3}$ particles well dispersed in silica matrixes [22,23] were obtained by in situ polymerization of a silica precursor (triethoxysilane or silicic acid) in an acidic aqueous sol of $\gamma$ - $\mathrm{Fe}_{2} \mathrm{O}_{3}$ particles. IR spectroscopic studies as a function of heat treatments of the xerogel showed that the particle surface and the solid matrix develop only weak interactions, via water molecules or hydrogen bonds, with no Fe-O-Si bonding. The silica matrix acts as an antisintering agent which stabilizes the $\gamma-\mathrm{Fe}_{2} \mathrm{O}_{3}$ particles against heating [24]. Whereas with uncoated particles the $\gamma \rightarrow \alpha-\mathrm{Fe}_{2} \mathrm{O}_{3}$ transformation starts below $300^{\circ} \mathrm{C}$ and is generally completed at 400 to $500^{\circ} \mathrm{C}$, in composites with sufficiently low particle concentration, no structural transformation takes place before the matrix crystallizes into cristobalite, above $1000^{\circ} \mathrm{C} . \gamma_{-} \mathrm{Fe}_{2} \mathrm{O}_{3}$ actually recrystallizes into $\varepsilon-\mathrm{Fe}_{2} \mathrm{O}_{3}$ which transforms into $\alpha-\mathrm{Fe}_{2} \mathrm{O}_{3}$. The structural characterization of the $\varepsilon-\mathrm{Fe}_{2} \mathrm{O}_{3}$ phase is in progress. In an inert atmosphere [22], the cleavage of $\mathrm{Si}-\mathrm{H}$ bonds in triethoxysilane-based composites allows to reduce the $\gamma$-Fe $\mathrm{O}_{3}$ particles into $\alpha$-Fe particles. As structural transformations of the matrix favour diffusion of embedded particles, a careful control of the dispersal of the $\gamma-\mathrm{Fe}_{2} \mathrm{O}_{3}$ particles in the starting composite is clearly prerequisite for obtaining heat-treated materials with controlled properties.

[1] Jolivet J.P., Belleville P., Tronc E., Livage J., Clays Clay Miner. 40 (1992) 531.

[2] Trone E., Belleville P., Jolivet J.P., Livage J., Langmuir 8 (1992) 313.

[3] Jolivet J.P., Tronc E., Vayssières L., Nanophase materials, G.C. Hadjipanayis and R.W. Siegel Eds. (Kluwer Academic Publishers, Dordrecht, 1994) pp.45-48.

[4] Jolivet J.P., Vayssières L., Tronc E., J. Colloid Interf. Sci. in press.

[5] Jolivet J.P., Tronc E., J. Colloid Interf. Sci. 125 (1988) 688.

[6] Trone E., Jolivet J.P., Nanophase materials, G.C. Hadjipanayis and R.W. Siegel Eds. (Kluwer Academic Publishers, Dordrecht, 1994) pp.21-28.

[7] Tronc E., Jolivet J.P., Magnetic properties of fine particles, J.L. Dormann and D. Fiorani Eds (North-Holland, Amsterdam, 1992) pp. 199-204.

[8] Tronc E. et al. Hyperf. Interact. 95 (1995) 129.

[9] Jolivet J.P., De la solution à l'oxyde, InterEditions, Paris, 1994.

[10] Cornell R.M., Clay Miner. 23 (1988) 329 ; Cornell R.M., Giovanoli R., Polyhedron 7 (1988) 385.

[11] Utsunomiya T., Hoshino Y., Show K., Mater. Res. Bull. 20 (1985) 85.

[12] Jolivet J.P., Massart R., Fruchart J.M., Nouv. J. Chim. 7 (1983) 325.

[13] Matijevic E., Pure Appl. Chem. 60 (1988) 1479.

[14] Stol R.J., De Bruyn P.L., J. Colloid Interface Sci. 75 (1980) 185.

[15] Sidhu P.S., Gilkes R.J., Postner A.M., J. Inorg. Nucl. Chem. 39 (1977) 1953.

[16] Jolivet J.P., Tronc E., Barbé C., Livage J., J. Colloid Interface Sci. 138 (1990) 465.

[17] Prené P. et al., IEEE Trans. Magn. 29 (1993) 2658 ; Cherkaoui R. et al., IEEE Trans. Magn. 30 (1994) 1098.

[18] Dormann J.L. et al., Phys. Rev. B 53 (1996) 14291 ; Proceedings of this Conference.

[19] Néel L., Ann. Geophys. 5 (1949) 99 ; Brown W.F. Jr., Phys. Rev. 130 (1963) 1677.

[20] Dormann J.L., Fiorani D., Tronc E., Adv. Chem. Phys. 98 (1996) in press.

[21] Dormann J.L., Bessais L., Fiorani D., J. Phys. C 21 (1988) 2015.

[22] Chanéac C., Tronc E., Jolivet J.P., NanoStructured Mater. 6 (1995) 715.

[23] Chanéac C., Jolivet J.P., Tronc E., J. Mater. Sci. in press.

[24] Tronc E., Jolivet J.P., Hyperf. Interact. 28 (1986) 525 ; Tronc E., Jolivet J.P., Livage J. Hyperf. Interact. 54 (1990) 737. 